\title{
Participatory multi-modelling as the creation of a boundary object ecology: the case of future energy infrastructures in the Rotterdam Port Industrial Cluster
}

\author{
Eefje Cuppen ${ }^{1} \cdot$ Igor Nikolic $^{2} \circledast$ - Jan Kwakkel ${ }^{2}$. Jaco Quist ${ }^{2}$
}

Received: 3 February 2020 / Accepted: 8 October 2020 / Published online: 24 October 2020

(c) The Author(s) 2020

\begin{abstract}
Finding leverage points for sustainability transformation of industrial and infrastructure systems is challenging, given that transformation is emergent from the complex interactions among socio-technical system elements over time within a specific social, technical and geographical context. Participatory multi-modelling, in which modellers and stakeholders collaborate to develop multiple interacting models to support a shared understanding of systems, is a promising approach to support sustainability transformations. The participatory process of modeling can serve as a leverage point by facilitating social learning amongst stakeholders, in which models can function as boundary objects that facilitate dialogue between stakeholders from different social worlds. We propose that participatory multi-modeling allows for the creation of a boundary object ecology, which involves a set of interacting and co-evolving boundary objects emerging throughout the modeling process. To explore this, we analyse the participatory multi-modelling process in the Windmaster project in the Rotterdam Port industrial cluster to understand which design choices were key to the creation of boundary objects. Our analysis shows that two types of design choices were key: design choices that enabled translations between participants, and those between participants and their organisation. We conclude that conceptualising participatory multi-modelling as a process of an evolving boundary object ecology, creating and adapting multiple interacting boundary objects provides a novel perspective that is useful for analysis and design of future participatory multi-modeling processes.
\end{abstract}

Keywords Boundary object $\cdot$ Participatory modelling $\cdot$ Sustainability transition $\cdot$ Transdisciplinarity $\cdot$ Energy infrastructure $\cdot$ Backcasting

\section{Introduction}

The transformation of industrial and infrastructure systems is key to solving sustainability problems like climate change, resource depletion and the increasing human environmental impact. Industrial systems and the infrastructures that enable them to function are complex socio-technical systems that involve highly diverse social entities (individuals,

Handled by Julia Leventon, Leuphana University Facultyof Sustainability, Germany.

\footnotetext{
Igor Nikolic

i.nikolic@ tudelft.nl

1 Universiteit Leiden, Zuid-Holland, Netherlands

2 Technische Universiteit Delft, Zuid-Holland, Netherlands
}

firms, governments, NGOs, etc.), institutions (law, regulation, norms, culture), as well as technical elements (pipelines, chemical factories, power grid, etc.), which all act and interact over time in a co-evolutionary way (Van der Lei et al. 2010). Finding leverage points for the transformation of such socio-technical systems is a challenging task, given that transformation is the emergent result of complex interactions between system elements over time. These interactions are governed by laws of nature, such as conservation of mass and energy, as well as by social rules, such as markets and laws. They involve a wide range of stakeholders, often with conflicting, individual and organizational rationalities and interests. Due to this complexity, any deliberate attempt at transformative change is a wicked problem (Rittel and Webber 1974), that is hard to solve due to the many diverse 
ways in which stakeholders understand both the problem definition and possible ways to address the problem.

Models and simulations are powerful tools for representing complex socio-technical systems and exploring the deep uncertainty intrinsic to wicked problems (Kwakkel et al. 2016; Lempert 2003; Calder et al. 2018). They can be used to systematically create a shared conceptualisation of a wicked problem, and systematically explore the possible consequences of decisions and events across many different scenarios. Such models typically include interactions between technical, organisational, institutional, and social dimensions. Given the complexity of the socio-technical systems, single perspective models are not able to capture all relevant dimensions and we must turn to multi-modelling. A multi-model can be understood as a collection of interacting models, each describing a specific part of reality from a specific perspective, providing stakeholders with a coherent, formalised and reproducible representation of the system of interest and its dynamics over time (Bollinger et al. 2018, 2015).

Especially when developed and used with stakeholders in transdisciplinary settings, such models can provide leverage by providing opportunities for alignment and social learning amongst stakeholders (Voinov and Bousquet 2010; Voinov et al. 2016; van Bruggen et al. 2019). According to Meadows (2008), one of the most effective leverage points for changing system behaviour is to change the mindsets or paradigms out of which the system arises. Participatory modelling is one of the ways in which such a change can be achieved.

Therefore, when dealing with wicked problems, the process of modelling is more important that the results of a model (Vennix 1999). Developing and using models with stakeholders has been given various labels, such as group model building, modelling with stakeholders, collaborative modelling, or participatory modelling (Voinov and Bousquet 2010; Barreteau et al. 2010, 2012; Basco-Carrera et al. 2017). Regardless of the exact label, the practice of modelling with stakeholders is gaining increasing attention in research and planning. For instance, participatory modelling has been used in environmental planning and environmental resource management such as in river basin management (Videira et al. 2009), air pollution (Yearley et al. 2003), water resource management (Castelletti and Soncini-Sessa 2007), and fisheries management (Rockmann et al. 2012).

If the participatory process is to be the leverage point for changing mindsets, and thus a leverage point for transforming industries and infrastructures, it is crucial to have a solid understanding of what these processes are and how they can be designed to be more effective. Several authors have used the notion of boundary object as a concept to explain how a model can facilitate interaction among various stakeholders in participatory modelling (Barreteau et al. 2012, 2013;
Jakku and Thorburn 2010). Boundary objects can be defined as (Star and Griesemer 1989) :

“...objects which both inhabit several intersecting social worlds [...] and satisfy the informational requirements of each of them. [...][They] are both plastic enough to adapt to local needs and the constraints of the several parties using them, yet robust enough to maintain a common identity across sites."

Boundary objects can thus provide interpretive flexibility to actors with different worldviews and rationalities, which allows them to collaborate or communicate despite different backgrounds, different understandings of results, or different meaning attached to the boundary object (Star and Griesemer 1989).

Although earlier studies (Barreteau et al. 2012, 2013; Jakku and Thorburn 2010) have shown that a model, as a boundary object, can facilitate interaction and joint sensemaking amongst stakeholders, it is not clear how a participatory multi-modelling process can deliberately be designed in a way that it delivers a model that functions as a boundary object. We contend that this requires the creation and interaction of several other boundary objects throughout the modelling process that, in a concerted way, enable a model to function as a boundary object, i.e. a boundary object ecology (see Section 2).

Therefore, in this paper, we address the following research question: What design choices are key to the functioning of a participatory multi-modelling process as a process of boundary object ecology creation, and what are implications for leveraging sustainable transformation of industrial systems?

In order to explore this question, we analyse the "Windmaster" case (Wurth et al. 2019), a project in which a participatory modelling approach was used to identify investment strategies for energy infrastructure development in the Rotterdam Port Industrial Complex (RPIC) in the Netherlands. The project was a collaboration initiated by several key stakeholders to explore the infrastructural requirements and options when more than $5 \mathrm{GW}$ offshore wind energy will have to be transported onshore in the region by 2030. The initiators included the Dutch gas and electricity transmission grid operators TenneT (TNT) and Gasunie (GAS), the regional distribution system operator Stedin (STD), together with the Rotterdam Port Authority (RPA), Siemens (SIM), industry representative Deltalinqs (DTL), The Institute for Sustainable Process Technology (ISPT), the Province of South Holland regional government (PZH) and Delft University of Technology (TUD).

The remainder of the paper is organised as follows. In Sect. 2, we elaborate on participatory modelling as a transdisciplinary process of boundary object ecology creation. In Sect. 3, we introduce the case of the Windmaster project in 
more detail and explain the methodology we use for analysing the participatory modelling process. Section 4 presents the analysis of boundary objects and key design choices in all phases of the Windmaster project.

Section 5 provides a discussion, reflecting on key design choices in the participatory modelling process, and suggesting avenues for further research. Finally, in section 6 conclusions are drawn.

\section{Participatory modelling as a process of boundary object ecology creation}

\section{Multi-models and participatory modelling}

Since large-scale transformations of industrial systems are an emergent outcome of interactions between social, technical, and physical elements, any model for supporting decision-making on large-scale transformations must have "requisite variety" (Ashby 1968), i.e. capture the key system elements and their interaction dynamics. It is impossible to adequately describe elements of complex systems using a single modelling formalism or mathematical techniques (Mikulecky 2001; Mitchell 2003). For example, describing the behaviour of interacting individuals requires a different formalism than calculating load flows in an electricity network or addressing the uncertainties of long-term developments and the ambiguities regarding stakeholder views and preferences.

Multi-modelling and multi-model ecologies have been suggested to support planning and decision-making on large-scale industrial transformation (Bollinger et al. 2018, 2015). Given the wicked (Rittel and Webber 1974) nature of realising intentional transformative change, any multi-model representation - regardless how accurate or detailed - will be a incomplete, biased, and contestable description, fraught with deep uncertainty (Walker et al. 2013) and ambiguity. Furthermore, unlike models of natural phenomena, which are based on laws of nature and can be used to produce predictions which can be validated by empirical experiments, models relevant for transformation of industrial socio-technical systems cannot be used in a predictive manner (Bankes 1993; Hodges 1991).

This raises the question: how can we make such models useful for decision-making? A variety of model-based robust decision-making approaches have been put forward in recent years in response to this question (Kwakkel and Haasnoot 2019; Herman et al. 2015; Walker et al. 2013). The common basis of these approaches is the use of systematic what-if analysis using computational experimentation, also known as exploratory modelling (Bankes 1993; Bankes et al. 2013; Kwakkel and Pruyt 2013).
There is a lot to gain from stakeholder engagement through participatory (multi-) modelling. Participatory modelling implies a process in which stakeholders and modellers develop and use models together. The structured, systematic, and collective activity of conceptualising, constructing, and using models by a group of stakeholders or stakeholders provides unique insights to the stakeholders and ample opportunities for social learning (Pahl-Wostl and Hare 2004; Henly-Shepard et al. 2015). This may lead to higher-order or second-order learning with regard to problem formulation and principal solutions to solve the problem (Argyris 2002). Such higher-order learning is required for paradigm change (Argyris 2002) and may thereby become a leverage point for system transformation (Meadows 2008).

\section{Boundary objects and translations between social worlds}

A boundary object "inhabits several intersecting social worlds and allows for translation between those worlds" (Star and Griesemer 1989). It is a "partial and temporary bridge which is fairly unstructured when used jointly and highly structured when used within one of the worlds involved" (Trompette and Vinck 2009). The concept of a boundary object is frequently used in studies on interdisciplinary and transdisciplinary collaboration (Nicolini et al. 2011; Feldhoff et al. 2019; Kimble et al. xxx) and modelling (Barreteau et al. 2013). Boundary objects can be physical (e.g a map or digital interface) as well as conceptual (a frame or concept, such as 'leverage point').

Sustainability transformation of industrial systems is a clear example of concerted action and interaction across various societal domains and social worlds; it extends beyond single organisations and sectors, thereby requiring new collaborations between organisations and sectors (Vernay and Boons 2015; de Bruijn and Tukker 2002; Niesten et al. 2017; Loorbach et al. 2017). Such collaboration can be challenging, because these stakeholders typically work in different sectors or institutional fields (DiMaggio and Powell 1983), where each stakeholder has its own culture, norms and practices and operates technical assets of vastly different natures. Boundary objects enable bridging different social worlds, allowing for collaboration between stakeholders within different institutional fields, from different organisations, and with different backgrounds, expertise, and rationalities (Trompette and Vinck 2009).

An organisation is embedded in an institutional field (Fig. 1). An institutional field is "a recognized area of institutional life: key suppliers, resource and product consumers, regulatory agencies, and other organizations that produce similar services or products" (DiMaggio and Powell 1983). Thus, an institutional field is a network of organisations. The 


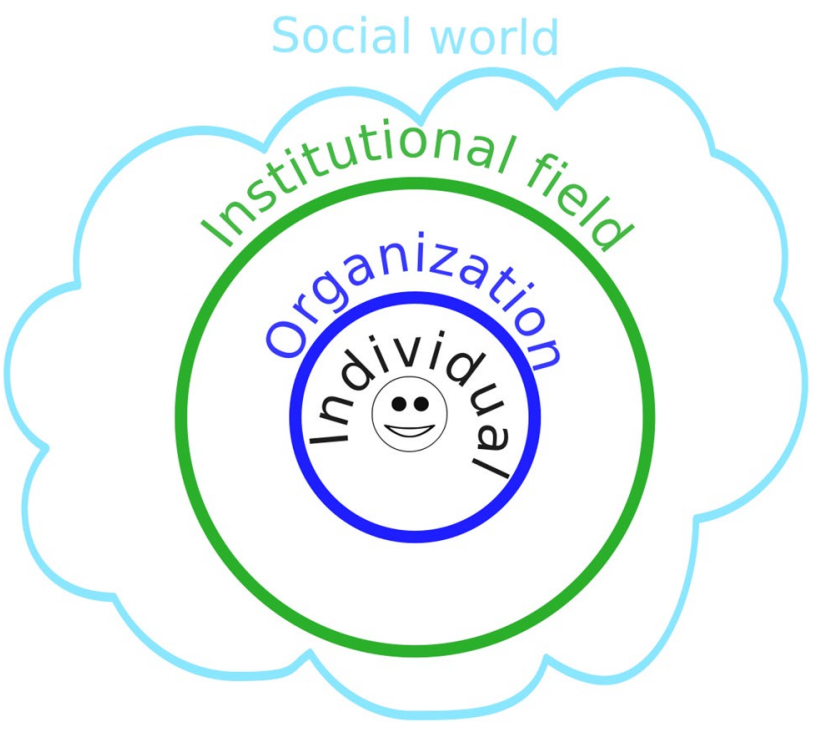

Fig. 1 Visualisation of relations between individuals, organisations and institutional fields

behaviour of individuals within organisations is shaped by both the organisation, and the institutional field.

Organisations and institutional fields can be considered different social worlds. Social worlds are "forms of communication, symbolization, universes of discourses, but also ... palpable matters like activities, memberships, sites, technologies, and organizations typical of particular social worlds." (Strauss 1982)(p. 121).

Individual participants are usually engaged in multiple social worlds simultaneously. An individual is embedded in (at least) two nested social worlds, the organisation and the institutional field (Green et al. 2008) (Fig.1).

In a participatory multi-modelling process these social worlds need to be bridged. Traditionally, analysis of participatory modelling processes focuses on a single boundary object, the model itself. We contend that, before a model can function as a boundary object, other boundary objects need to emerge, which together create a boundary object ecology. In this, the multi-model can be viewed as a boundary object ecology that overarches and ties together a collection of boundary objects that emerge during the participatory modelling process.

An ecology can be defined as a totality or pattern of relations between organisms and their environment. A boundary object ecology, represented in Fig. 2 can then be described as an interacting group of boundary objects that interact and co-evolve with one another within the context of a dynamic participatory process. The ecology perspective on boundary objects points to the temporal distribution of these objects, and the co-evolutionary process through which they get constructed. The first boundary object created becomes the environment within which

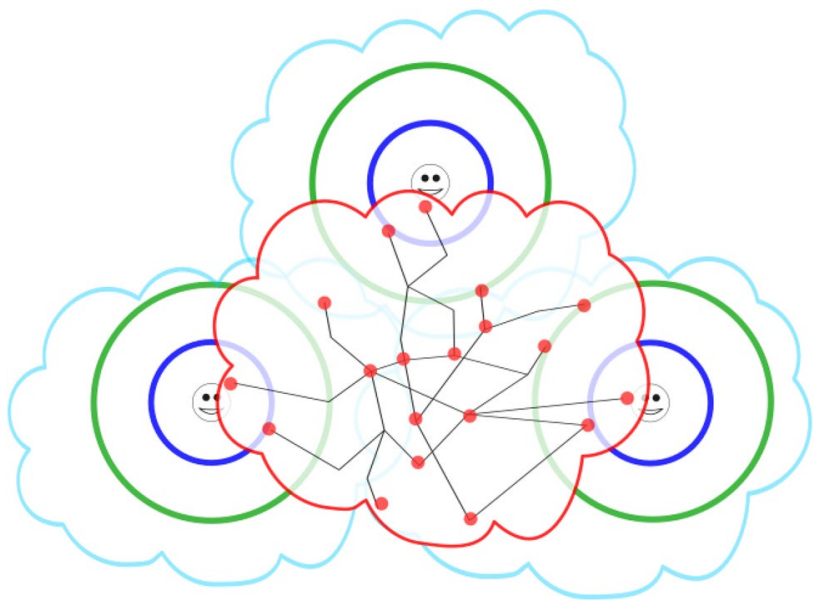

Fig. 2 Boundary objects (red connected dots) consisting of a boundary object ecology (red cloud)

the second one is developed, and thus shapes its form and function. One can use this aspect to deliberately try to shape the participatory process by focusing on the order in which boundary objects emerge.

Figure 2 visualises the conceptual framework that will be used for our analysis. It shows how a boundary object ecology enables interactions between participants from different organisations and institutional fields, allowing for learning and translations between different levels of organisation (individual, organisation and institutional field) as well as social worlds. Note that organisations may be part of one or more institutional fields; for the sake of clarity we have separated these in Fig. 2.

In the next section we will introduce the case study in more detail, and then proceed with our analysis based on the conceptual framework presented here.

\section{Case study}

\section{The Windmaster project}

The Rotterdam Port Industrial Cluster (RPIC) is one of the worlds largest petrochemical clusters, and has a correspondingly large environmental impact, producing approximately $30 \%$ of all Dutch greenhouse gas emissions. This cluster has to undergo a fundamental transformation in order to contribute to the Dutch climate goal of $49 \% \mathrm{CO}_{2}$ reduction in industry in 2030. One potentially feasible transformation pathway is through electrification of hydrogen production and industrial heating and cooling, which could reduce overall $\mathrm{CO}_{2}$ emissions of the RPIC by $70 \%$. This development is supported by expanding production of renewable electricity in offshore wind parks on the North Sea in the next decade. 
By 2030 , roughly $5 \mathrm{GW}$ electricity from offshore wind parks is expected to arrive onshore at the RPIC every year. While this may seem as a vast amount of electrical energy, it is a relatively small fraction of what is needed for industrial electrification. Furthermore, the capacity of the existing electricity infrastructure is inadequate by two orders of magnitude for accommodating this influx of additional electricity. Investments in high-voltage transmission and distribution networks is complicated by long investment times, high investment costs, limited space and rigid, non-adaptive and highly resilient institutional arrangements. This is further complicated by the fact that industry investments in electrification depend on availability of infrastructure, while infrastructure investments rely on industrial demand, resulting in a waiting game among relevant stakeholders.

The regional energy infrastructure providers have to facilitate decarbonisation in the RPIC and the increasing offshore electricity production at the same time, which calls for infrastructure investment strategies that are robust in the face of these major uncertainties and complexities. This was addressed in the Windmaster project, which ran from late 2018 till summer 2019. Windmaster focused on the question how to handle the $5 \mathrm{GW}$ of offshore wind electricity onshore in the Rotterdam RPIC region, while also enabling decarbonisation. The overall aim of the project was to develop and test a participatory multi-modelling approach for identifying robust investment strategies for future energy infrastructure in the RPIC. The project was considered by the stakeholders as a pilot project, and the participatory modelling process was framed as a proof-of-principle. The motivation for this framing was that showing the potential usability of participatory multi-modelling for supporting supra-organisational decision making on energy infrastructure investments could mobilise more substantive funding for in-depth follow-up research. The project was envisioned as a leverage point that would set in motion a novel approach to infrastructure development, able to solve the current locked-in situation. Wurth et al. (2019) provides a detailed overview of the project, its methods, and its results.

As the offshore wind electricity can be converted into hydrogen, the project considered (i) the existing natural gas/ future hydrogen-grid from GTS (Gasunie), in addition to (ii) the electricity distribution system of Stedin; and (iii) the High Voltage electricity transmission system ran by the Dutch national grid operator TenneT. There are various other relevant energy networks in the RPIC, such as networks for high and low temperature steam, but given the proof-of-principle nature of the project and the limited time and capacity available these were considered out of scope.

The participatory multi-modelling process fused the expertise of the authors on participatory visioning, backcasting and stakeholder engagement (Quist and Vergragt 2006; Ligtvoet et al. 2016; Breukers et al. 2014; Cuppen 2012a; van der Voorn et al. 2007; Quist 2013) participatory multimodelling (Nikolic et al. 2019; van Bruggen et al. 2019; Bollinger et al. 2018, 2015), adaptive pathways (Haasnoot et al. 2013) deep uncertainties (Walker et al. 2013; Kwakkel et al. 2010)and co-creation and constructive conflict in stakeholder dialogues (Cuppen 2012a, b; Cuppen et al. 2010) The authors designed the participatory multi-modelling process, implemented the models, facilitated the workshops and conducted the analyses.

\section{Participatory multi-modelling in Windmaster}

Participation is a broad term that can refer to different levels and types of engagement (Arnstein 1969; van Asselt Marjolein and Rijkens-Klomp 2002) In the case of Windmaster, participation referred to interactive (Pretty 1995)and iterative engagement with stakeholders in the multi-modelling process (Voinov and Bousquet 2010; Voinov et al. 2016; Barreteau et al. 2013) or co-learning (Lynam et al. 2007) Participation involved all steps of the process, from the identification of project goals to the presentation of results to decision-makers.

The participatory multi-modelling process used in the Windmaster project consisted of four phases: (1) a preproject proposal, (2) qualitative modelling, (3) quantitative modelling and (4) a sense-making phase. The qualitative phase involved participatory visioning, backcasting, and system decomposition in three workshops of half a day. The quantitative phase started with the participatory conceptualisation and evaluation of the multi-model, followed by the computational exploration of deep uncertainties. The sense-making and finalisation phases included a participatory sense-making meeting for interpreting the results from the computational exploration, and a closing session.

Table 1 shows the steps in the process and the stakeholders that were involved in each step. All participants of the workshops represented stakeholders who had co-funded the project. At least 3 of the authors were always present; 2 to run the workshops in collaboration with a person from Siemens and a person from the regional infrastructure operator who joined the core team, while other authors observed and made notes.

For the analysis presented in this paper, we collected data through participant observation of the workshops. This enabled observations during the workshops around moments in which there was discussion about choices within the process, and reflection on those through the lens of our conceptual framework. We also used other data sources, such as written documents from the meetings, our own notes made during workshops and intermediate meetings with the research team, as well as various communications and face-to-face meetings with the participants in the project. 
Table 1 Steps in the modelling process and participants involved. Organisations are denoted by their acronym, defined in Section 1. If more than one person from a organisation is present, their number is denoted in brackets

\begin{tabular}{lll}
\hline Project phase & Activity & Participants \\
\hline Proposal & In-person and teleconference meetings & TUD, SIM, TNT, GAS with all other participants, various attendance \\
Qualitative & Visioning workshop & TUD (4), SIM (3), TNT, GAS, RPA ,STD, DTL, PZH \\
& Backcasting workshop & TUD (4), SIM (2), TNT (2), GAS, RPA, DTL, STD, PZH, ISPT \\
& System decomposition workshop & TUD (2), SIM (2), TNT (2), GAS, RPA (2), STD, PZH \\
Quantitative & Data collection & Individual meetings TUD and SIM with TNT, GAS, RPA,STD \\
& Multi-model construction in 2-day hackathon & TUD (3), SIM (2), TNT (2), GAS, RPA, PZH, STD \\
Sensemaking & Sensemaking session & TUD (4), SIM (3), TNT, GAS, RPA, PZH, STD \\
& Closing session & TUD (4), SIM (2), TNT, GAS, RPA, DTL, PZH, STD, ISPT and \\
& & several other interested organisations \\
\hline
\end{tabular}

Based on this data we could retrospectively identify those boundary objects and design choices that enabled "moments of translation" (see Sect. 2.2) in the participatory modelling process. Moments of translations are empirically visible as moments in which participants overcome a situation of conflict, diverging views or challenges. This means that moments of translation could only be identified in hindsight, as without knowledge of how the process unfolded over time, it is impossible to assess whether translation took place. We did this through iterative discussions amongst the author team, and reflecting on the data using our conceptual framework in Figs. 1 and 2 . For each phase of the project we identified whether and which boundary objects played a role in the translations.

The four phases (Table 1) are used to structure our analysis in the next section. It is organised in two parts: (i) description of the activities in the phase, including key design choices; (ii) analysis of how these design choices contributed to the emergence of boundary objects.

\section{Analysis}

This section describes the four project phases in detail using the conceptualisation presented in Sect. 2.

Each of the four project phases involves different types of translations and boundary objects. The proposal phase involved translations between the boards of the involved organisations and the modellers/research team, and between participants and the modellers/research team. In the qualitative phase, translations were taking place between participants, so more on the individual level, as well as between the boards of the organisations around the $\mathrm{Go} / \mathrm{No}$ Go decision at the end of this phase. The quantitative phase involved translations between participants, as well as translations between participants and modellers.
In the sense-making and finalisation phase a new type of translation emerged, namely between participants in the process and their own organisation (colleagues and boards). Figure 3 presents the various translations and the evolving boundary object ecology throughout the project.

\section{Proposal phase}

The proposal phase involved (Fig. 3) the creation of the initial boundary object ecology, through interactions between organisations with closely related institutional fields and broadly overlapping social worlds. A small number of individuals were closely involved in shaping the initial boundary objects. The involved organisations formed a consortium and started the project.

\section{Description of activities}

For the stakeholders, each of the three core concepts of our participatory multi-modelling approach was new, in order of increasing novelty: multi-modelling, participatory modelling, and exploratory modelling under deep uncertainty. This high degree of perceived novelty constituted uncertainty about the utility of the approach. In particular the exploratory modelling approach under deep uncertainty was challenging for infrastructure operators, who traditionally strongly emphasise stability, predictability, and maintenance. The proposal stage was therefore key to developing joint understanding, support and commitment from the involved stakeholders.

Over a number of iterations with a core group of stakeholders (TUD, SIM, TNT, GAS, see Table 1), a slide pack was produced containing the project narrative supported by visualisations. This slide pack was a boundary object that resulted from dialogue within the core group; it captured their joint understanding of what the project should be about. It was made in such a way not only to enable translation 


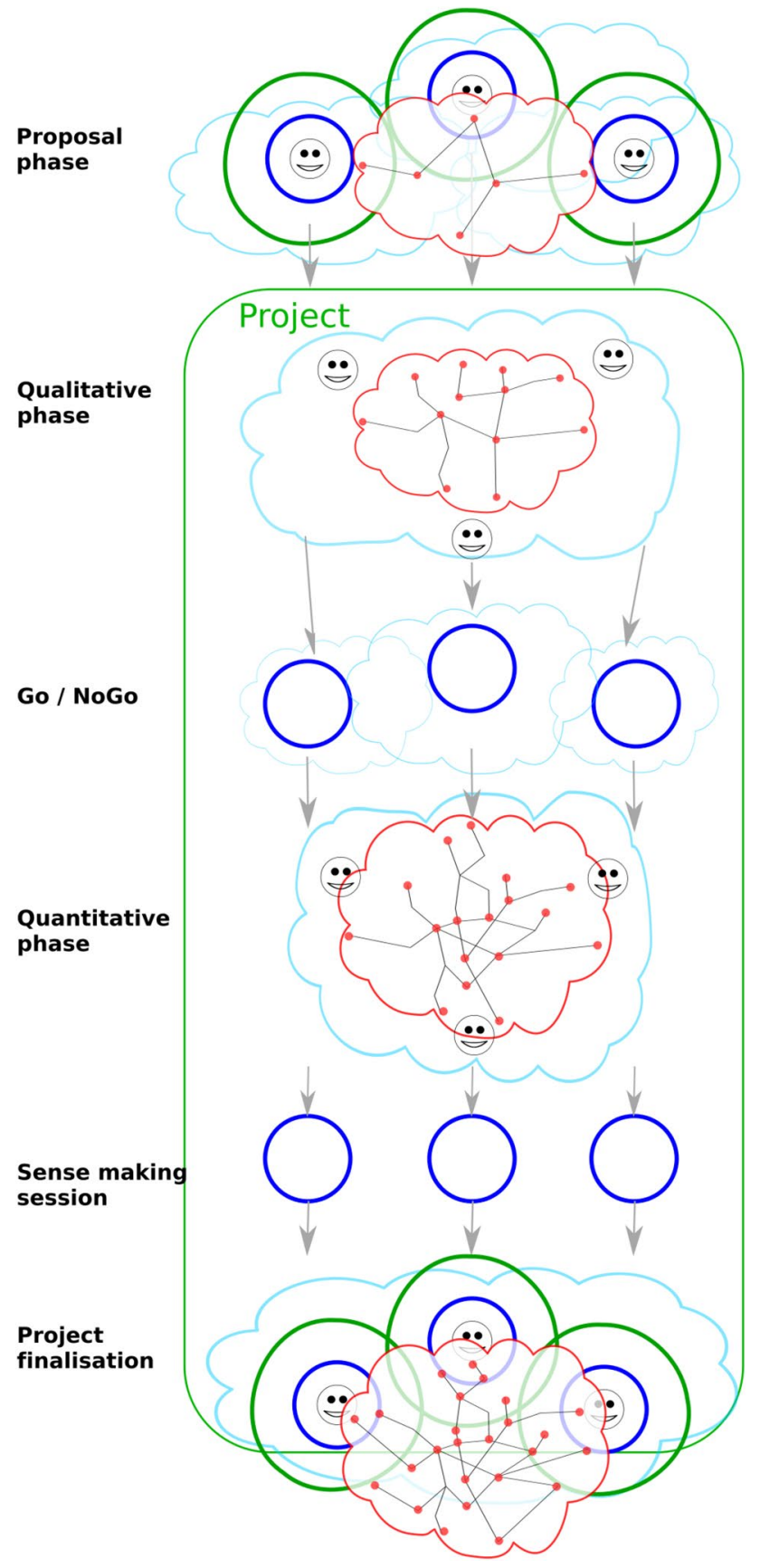

Fig. 3 Transformations and boundary object ecology development (red cloud) throughout the project. Participants (faces) engage in different social worlds (blue clouds), are part of an organisation (blue circles), and embedded in an institutional field (green circle)

amongst the individuals involved in the core group, but also to their organisations, as to create organisational support for the project. Once the slide pack was available, a more detailed discussion on the scope and process could start.

The first key decision was to define a relatively small and short project. This would allow for delivering a proofof-principle of the approach. This was followed by setting spatial and infrastructure boundaries, which was relatively easy, given the natural bounds of the RPIC, and selecting the most relevant infrastructures, related to electricity, natural gas, and hydrogen.

Next, a conceptually much more challenging question surfaced. How to represent changes in energy demand from the many industries in the RPIC? A straightforward way to model this would entail endogenously modelling the decision-making processes of many international companies, including the technical characteristics of more than 200 of their current production assets in the RPIC, and their decision on which of the many novel technological options available they would implement and when. This level of detail is highly relevant, as the involved technical assets have such large energy consumption that any change would have a significant impact on the energy infrastructure requirements.

Though stakeholders were greatly in favour of this conceptually straightforward modelling approach, developing the models this way would also imply a daunting modelling challenge, which would not be feasible within the scope and timeline of the envisaged pilot project. Therefore, the research team proposed a radically different approach. All changes in energy use and technological options were proposed to be exogenous to the model, and would be addressed in the deep uncertainty analysis. It amounted to identifying a large scenario space spanning every possible decision that could lead to any possible sequence of demand changes over time. Figure 4 illustrates the concept of scenario space, where each pathway towards 2050 , starting today is one possible sequence of energy demand changes driven by company decisions.

The scenario space approach greatly reduces model complexity at the expense of increased computational cost. There are approximately $10^{16}$ possible pathways, which would require vast amounts of time (in the order of thousands of years of computation) to explore completely. Using advanced statistical sampling techniques (Kwakkel and Pruyt 2013) only a small fraction of these paths needs to be analysed in order to provide robust results. These two approaches to modeling changing energy demand deliver the same functional outcomes, exogenising demand is in essence an advanced modelling "dirty trick", which was unfamiliar to the involved stakeholders. This modelling choice required extensive explanation, which substantially increased the uncertainty of stakeholders about the feasibility of the project and the usefulness of the outcomes.

The final scoping discussion in the pre-project phase was about the time horizon of the scenarios and simulations. Two different time periods were considered: a 10-year horizon ending in 2030, and a 30-year horizon ending in 2050. For the involved stakeholders this was a major issue. Ten years ahead is a natural horizon for large-scale infrastructure projects, but this time horizon is meaningless from the 
Fig. 4 Visualisation of the deep uncertainty concept, used to communicate exogenous company decisions. A,B,C etc are specific company decisions that could(not) happen at some point in time. The permutations of these (non)events creates a vast combinatorial space, with each specific sequence of events being a possible transition pathway

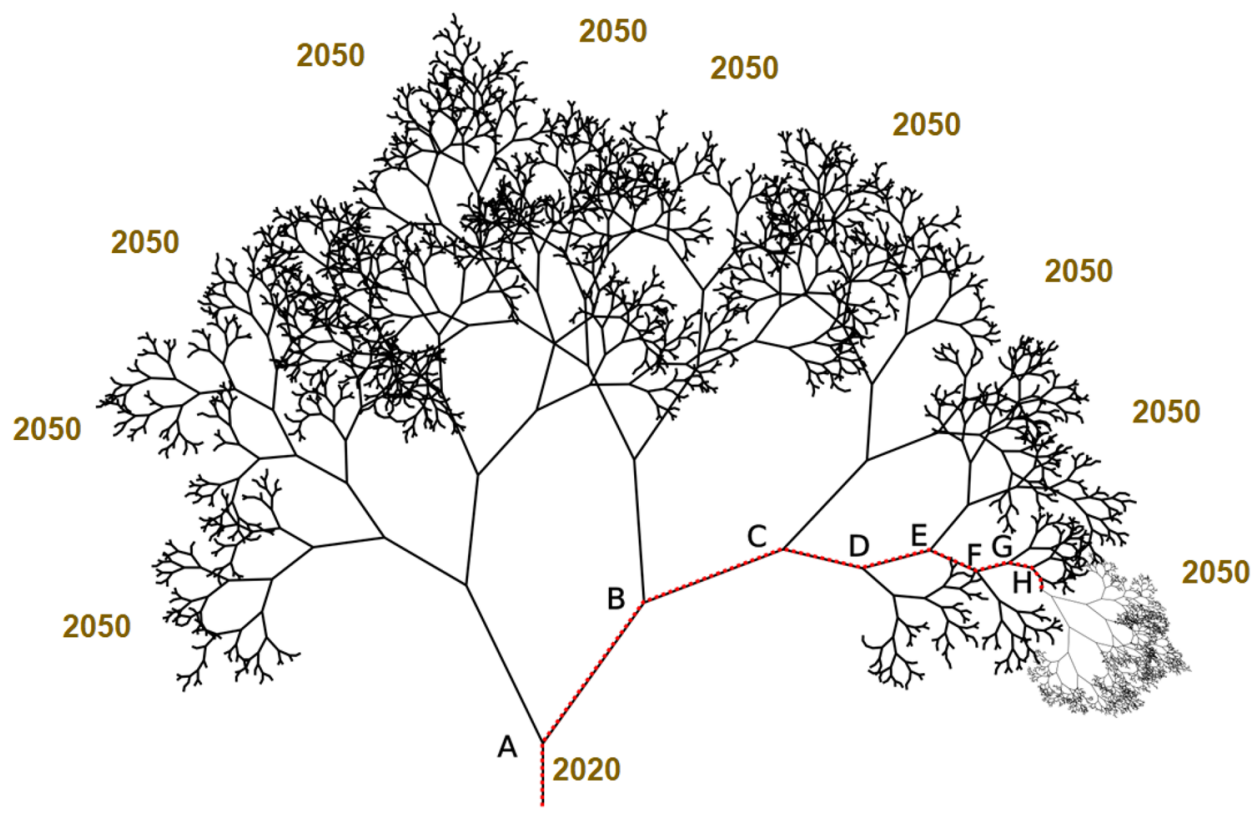

modelling and decision making under deep uncertainty perspective. The year 2050 is given as a boundary by the Paris agreement and government policy and is an obvious choice. However, it is 'very far away ' for the stakeholders involved, as their investment horizons are shorter term. One of the individuals involved "completely understood the need for 2050, but feared to be laughed at back at the office when agreeing to a time horizon of 30 years". In the end, it was decided that the project would proceed with a 2030 horizon, but the 2050 horizon would also be explored where possible, but would not be considered as a project deliverable.

Once the project plan was complete, with all modeling and scoping choices settled, it was presented for approval to the responsible boards of the funding stakeholder organisations. At that moment, the novelty of the approach and thus uncertainty about what the project would deliver was raised again. On the request of the stakeholder organisations this was solved by adding a Go/No Go decision halfway in the project. This proved to be an important decision later on in the process (see Sect. 4.2.2).

\section{Key design choices, boundary objects and translations}

The key design choices and boundary objects are summarised in Table 2.

Several boundary objects were constructed during the proposal phase, presented in Table 2. As evolving objects, all four show clear characteristics of a boundary object that helped participants and the research team to "negotiate their differences and establish agreement on their respective points of view" (Trompette and Vinck 2009) Several of these boundary objects concern specific process design choices, most notably the uncertainty space visualisation and the 2030 time horizon. The decision to use the time horizon of 2030 'with an optional exploration towards 2050' served to negotiate the different meanings of 2030 ("too short to do meaningful analysis" versus "in line with investment horizon"). As a boundary object, it allowed for translation between the modellers and the senior decision-makers at the organisations involved. The visualisation of the adaptive pathways tree in Fig. 4 turned out to be a key boundary object for communication, that helped to explain the nature of the modelling approach and the type of insight that could be achieved.
Table 2 Proposal phase key design choices and boundary objects

\begin{tabular}{ll}
\hline Key design choices & Boundary objects \\
\hline - Combining specific scientific concepts & • Proposal slide pack \\
- Framing the project as a proof-of-principle & $\bullet$ Project specification \\
- Choosing for Exogenous company dynamics and adaptive pathways & $\bullet$ Uncertainty space visualisation \\
'tree' & $\bullet$ \\
- Choosing for dual 2030/2050 time horizon & \\
- Introducing of a Go/No Go moment & \\
\hline
\end{tabular}




\section{Qualitative phase}

During the qualitative phase (Fig. 3), a new social world consisting of individual project participants was created. The initial boundary object ecology was used to develop new but related boundary objects. Project participants were involved in creation of these boundary objects, but were not fully engaged, pending the Go / No Go decision. Participants translated the qualitative phase outcomes to their organisations, leading to a collective Go decision.

\section{Description of activities}

The qualitative phase was meant to support a shared understanding of the future, through the development of a shared set of visions and associated transition pathways. These visions and pathways were suppose to facilitate communication and collaboration among the involved participants, and as such, function as boundary object. The phase consisted of a visioning workshop, a backcasting workshop, and a system decomposition workshop. Each workshop was attended by one or two participants from each organisation.

Before the workshop, a questionnaire was filled in by participants, in which participants were asked about issues, interests and motivation, key aspects, preferences, trends and expectations. Based on these inputs, the research team proposed 4 visions, using two dimensions resulting in a 2x2 matrix: (1) the growth of fossil cluster in RPIC versus the decline of fossil cluster in RPIC, and (2) minimal hydrogen produced from wind energy versus maximum use of hydrogen. The idea was that with this two-dimensional space the visions would cover divergent futures. However, during the visioning workshop it appeared that participants considered the minimal use of hydrogen as less interesting and less relevant.

As a result, the following two visions were further elaborated by the stakeholders in the workshop: (1) decline of the fossil cluster, while using as much hydrogen produced as possible, and (2) growth of the fossil cluster, also using as much hydrogen produced as possible (see text boxes Future vision 1 and 2).

Interestingly, in this workshop, the discussion about the time horizon of the project arose again. All participants agreed that it would not be useful to take the year 2030, as 10 years is too short for the large infrastructural changes that were explored in the project. The participants explicitly mentioned that 2030 is just one investment cycle and would therefore be of limited use. Therefore it was decided to use 2050 as a time horizon for the visions.

Future vision 1 - High amounts of $\mathrm{H}_{2}$ produced from wind, decline of fossil cluster: Recycled plastics will be introduced in the beginning of 2020. These sustainable plastics will be produced using recycling techniques such as waste to chemicals. By 2030 some factories with oil as a feedstock, including refineries will be closed down leading to a (temporarily) smaller RPIC . Electricity production from coal is phased out. Offshore wind allows for the production of green hydrogen. By 2030, 5 GW of energy will be produced from off-shore wind farms. Until then, blue hydrogen (hydrogen produced from natural gas in combination with $\mathrm{CO} 2$ storage and utilisation) will occupy an important position. There will be an infrastructure for transport of blue hydrogen that can later be used for green hydrogen (hydrogen produced from wind). At maximum production, 1 to $2 \mathrm{GW}$ of wind energy will be generated for the supply of hydrogen. The remaining 3 to $4 \mathrm{GW}$ of the total $5 \mathrm{GW}$ of offshore wind can be converted into electricity, heat and steam. Buffer capacity can be created through the storage of compressed hydrogen or the production of synthetic fuels. The hydrogen infrastructure will be managed by an independent party such as Gasunie. The industrial culture will gradually become more hydrogen-oriented and the grid operators will proactively invest in this.

Future vision 2 - High amounts of $\mathrm{H}_{2}$ produced from wind, growing fossil cluster: Growth in fossil means an increase in investment in oil refineries in the Port of Rotterdam. This growth will be accompanied by an increasing demand for hydrogen as a result of hydro-cracking. It is expected that this will increase the demand for hydrogen by 660 MW H2. In the period up to 2030, a methanol plant will be built. This will lead to an additional hydrogen demand of almost 300 MW (peak power), while the current gas plants will also switch to hydrogen. These plants will serve as a backup in times of low wind. Because there is an increase in the heavy oil conversion capacity, there is also an increase in residual gases. These gases will be used for additional heat demand. It is assumed that existing Steam Methane Reformers (SMRs) at oil refineries are replaced by water electrolysers. Existing SMRs of current gas produces will remain in place until around 2030. Little cultural change is expected in the industry, but the replacement of SMR by hydrogen capacity is expected to be a step towards a 'greener' awareness in the industry. The infrastructure managers will have to invest in hydrogen infrastructure. In order to have a hydrogen infrastructure ready in time, pre-investments are needed, while these are not typically done in business-as-usual decision-making at infrastructure companies.

The second workshop focused on backcasting (Vergragt and Quist 2011)and pathway development towards the two visions, detailing the changes and activities that needed to be undertaken in order to realise the visions. Identification of changes was structured using four categories of changes: a) technical and infrastructural changes, b) economic and policy changes, c) cultural and behavioural changes, and d) organisational changes. Changes for both visions were put on a timeline, while the infrastructural changes were first 


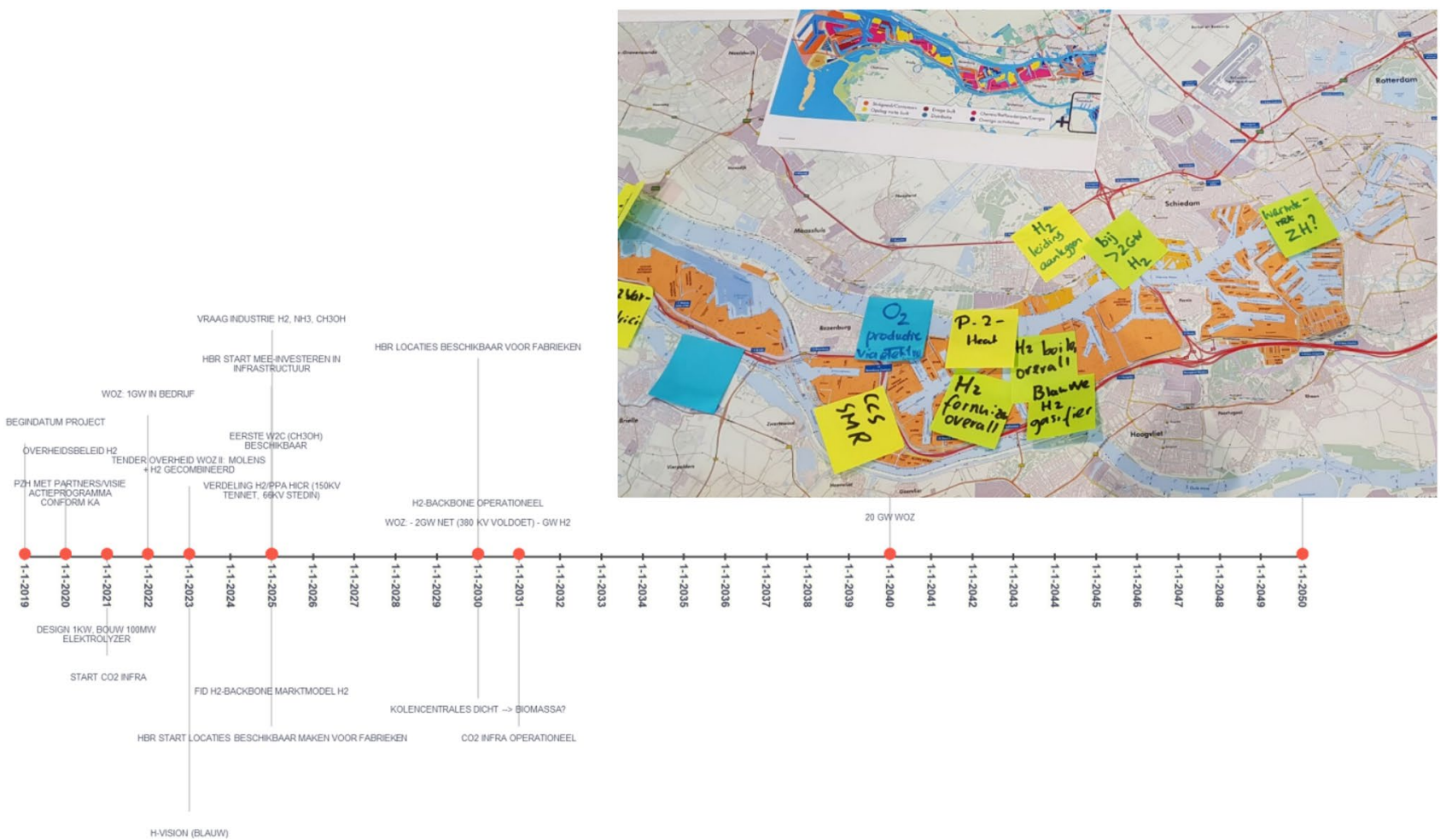

Fig. 5 Example of a pathway map and transition timeline. Image aims to demonstrate the nature of the boundary object, transition pathway details are outside the scope of this paper

Table 3 Qualitative phase key design choices and boundary objects

\begin{tabular}{ll}
\hline Key design choices & Boundary objects \\
\hline - Creating visions and pathways & $\bullet$ Vision map and timeline \\
- Choosing for 2050 timeframe & $\bullet$ Go/No Go document \\
\hline
\end{tabular}

located on a map of the RPIC, before positioning on a timeline; see Fig. 5 for an example of one such timeline.

The third workshop was a system decomposition workshop and served as a bridge between the qualitative and quantitative phase. This workshop aimed at collecting relevant qualitative data from the participants about decision making processes within their organisations on infrastructure investments and at identifying specific infrastructure investment options. The qualitative phase was ended by the Go/No Go moment. All parties decided positively.

\section{Key design choices, boundary objects and translations}

Table 3 summarises the key decision choices and boundary object in the qualitative phase.

The first two workshops of the qualitative phase resulted in two visions and pathways. The visions and pathways served as boundary objects facilitating translations between participants in the workshops, including the research team.
Their creation and form was strongly influenced by the scenario space perspective (Fig. 4) which provided both the concept and a visual language for the pathways created during the workshops. In retrospect, the visions and pathways helped to further engage stakeholders with the quantitative modelling in the next phase, where the same logic of scenarios as sequences of events was used. The choice to change the time horizon to 2050 shows that indeed translations in this phase were mainly between participants. Apparently, at this point, participants were not concerned with translations to their organisation (that would again come at the $\mathrm{Go} /$ No Go), but looked more strategically into the longer-term future which requires more than one investment cycle.

The decision in the pre-project phase to have a Go/No Go moment played an important role in the way the project progressed. The Go/No Go decision set several mechanisms into motion. First, it raised the stakes for everyone involved, as a No Go would reflect badly on individuals involved in the project, and the collaboration as a whole. Second, as the project arrived at that point, curiosity and sunk cost thinking became apparent: "Well, we spend all this time talking, I am curious how you will translate this into something that works?". Finally, it led to the creation of another boundary object; the project team made a Go/No Go document for the individual participants to take back to their organisations and convince their organisations of the merits of continuation. 
Interestingly, the Go/No Go moment appeared as a moment of translation between modellers and participants on the one hand, and between participants and the senior decisionmakers at their organisations on the other hand. It became an "obligatory point of passage" (Callon 1984) as once jointly agreed upon, all participants and their organisations committed to the project and its approach for the quantitative phase.

\section{Quantitative phase}

The quantitative phase saw a deep involvement of the participants (Fig. 3) with active co-creation of new boundary objects, and further development of existing ones. The project social world was strengthened by frequent and intensive collaboration during hackathons.

\section{Description of activities}

The quantitative phase is conceptually and structurally based on the modelling cycle (Dam et al. 2013) which the stakeholders were broadly familiar with. Elements critical for modelling, such as the problem identification and scope definition, were discussed extensively in the pre-project phase. Notable was the use of the XLRM framework (Lempert 2003) as a precise statement and visualisation of the modelling tasks, presented in Fig. 6 .

The quantitative phase consisted of two parallel processes: data gathering and multi-model construction. The data gathering process started with iterative identification and formalisation of the basic model elements necessary to describe the RPIC, its infrastructure and how the infrastructure might change. A small team, a researcher and a stakeholder working for one of the infrastructure providers, developed the basic ontology (or formal vocabulary) of the model, which enabled structured collection of data. The created data set combined public and open data sources and data provided by the infrastructure providers. The data set is unique in its scope and detail, describing all major energy conversion assets in the RPIC, such as furnaces, boilers and electrolysers, and infrastructure assets like pipelines, transformers and powerlines. Figure 7 presents a high-level overview of the dataset. While the details are not relevant for this paper, notable is the holistic perspective of all involved energy carriers, infrastructures and production/consumption

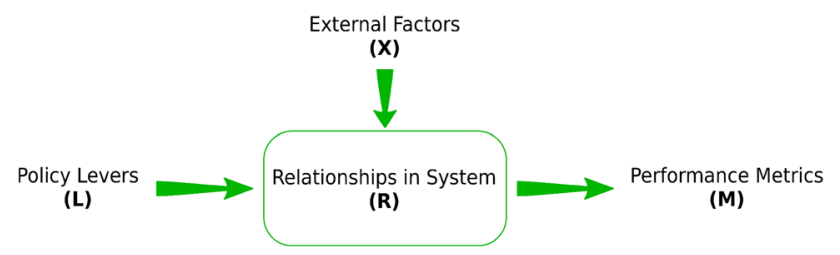

assets. Given the high silo perspectives on infrastructure and industry, no single stakeholder had perceived the RPIC energy system this way before.

Multi-model construction Throughout an intensive twoday process, set up as a hackathon, the individual parts of the multi-model were conceptualised, and the inter-model communication protocols were set up. The three infrastructure providers jointly defined and developed the technical models of the high and medium voltage grid, and the gas grids for $\mathrm{H}_{2}$ and natural gas. The decision was made not to use existing, highly detailed technical models, and appropriate simplifications were created. Discussing the multi-model and the myriad of technical design choices involved is outside the scope of this paper; a detailed description is provided by Wurth et al. (2019). Figure 8 presents a high level schematic overview of the created multi-model.

Two key elements in this phase are of particular relevance: the scenario space construction, and the definition and visualisation of the key model metrics.

As discussed previously, a key early modelling choice was to treat all dynamics related to how industries in the RPIC decide on when and how to change their conversion assets as exogenous to the model. In technical terms, this means that the multi-model describing the infrastructure development in the RPIC is forced by a time series of events describing changes in conversion assets. An example series is: in 2025 , refinery $\mathrm{X}$ closes, in 2026 gas fired boiler $\mathrm{Y}$ is replaced with a electrical boiler and furnace $\mathrm{Z}$ is converted to hydrogen. These series of events up to 2050 are identical in form to the visions and pathways (Fig. 5) constructed in the qualitative phase. Communicating both the modelling choice and associated analysis techniques took a significant amount of discussion during the hackathons, and required that after the hackathons a small-sub team spend several days identifying the relevant dimensions and constraints in order to construct a plausible space from which to sample.

The second element is the definition of key model metrics and their visualisation over many plausible futures. What is a sensible metric for the success or failure of various policy options in supporting the energy transition under a very large number of plausible futures? Since the way the model is used was quite unorthodox compared to how the stakeholders normally use models, the usual key performance indicators were not suitable. After extensive discussion, a negative definition of success was adopted. A policy was good if it led to the least number of missed events from the pathway of events, i.e. potential changes in demand that could not be accommodated because of infrastructure transport capacity limitations.

Fig. 6 The XLRM framework 


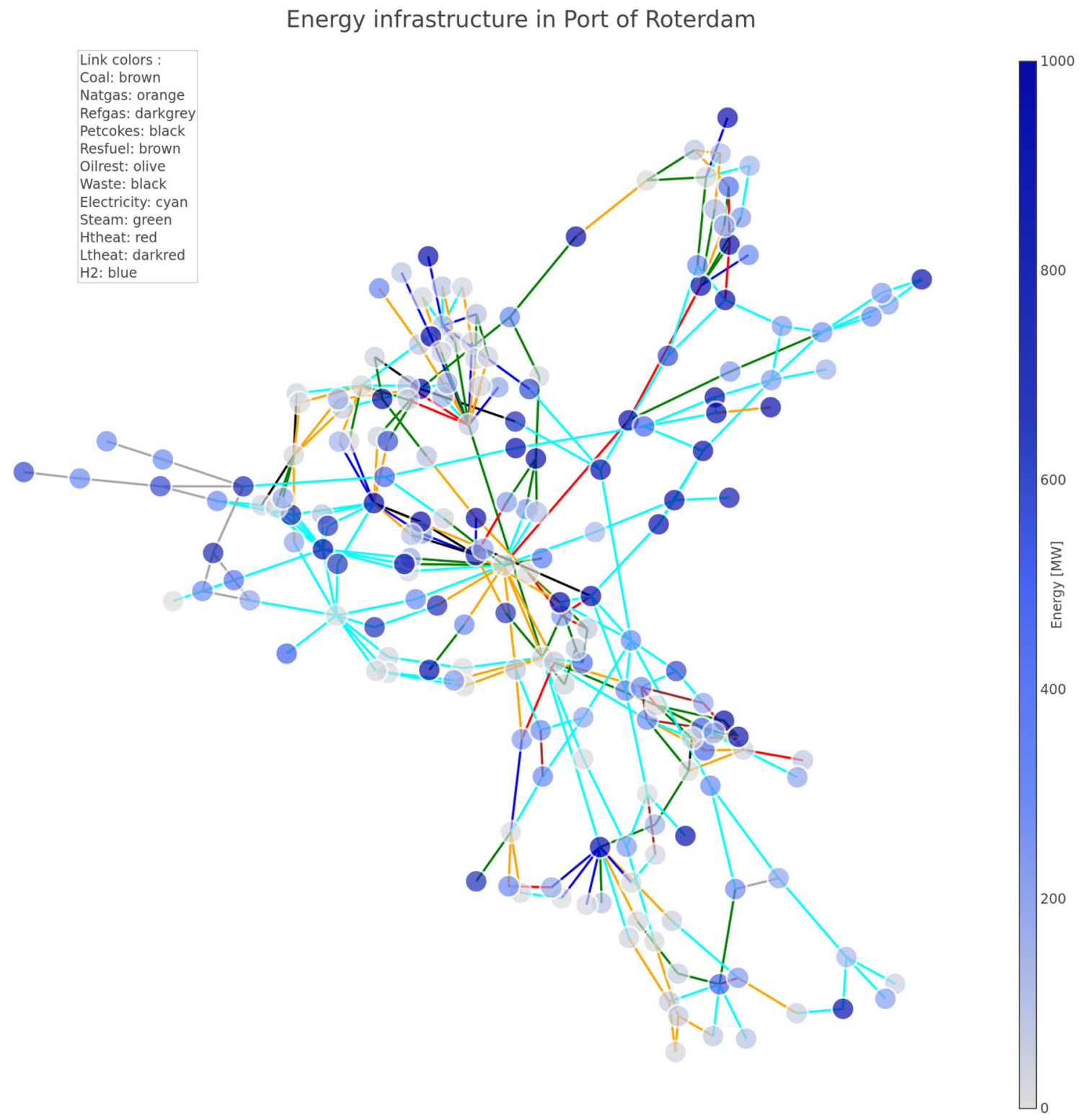

Fig. 7 High level overview of the energy system in the Rotterdam HIC. Dots are various energy conversion assets and energy infrastructure elements. Colours denote different type of energy carrier. Image

\section{Key design choices, boundary objects and translations}

Table 4 presents the key design choices and associated boundary objects during the quantitative phase.

The quantitative phase resulted in a ontology for the model, a data-set, the implemented multi-model, and a series of visualisations of model results. Translations in this phase involved primarily translations between participants and modellers while developing the multi-model. We observed that the visions and pathways from the qualitative phase primed the participants for thinking in terms of series of events in this phase. provided to demonstrate the nature of the boundary object, energy system details are outside the scope of this paper

The last boundary object, missed events metric visualisation, is particularly notable. Probabilistically expressing the non-delivery of infrastructure services, preventing possible futures from happening, is substantially different than the usual metrics. It created a space for discussing the deep uncertainties surrounding transformations to sustainability. Because this metric was so different, it turned out to be a non-threatening way for the infrastructure providers to discuss their internal decision-making and how to accommodate different plausible futures. The energy system data visualisation was also notable, because it not only served as translation between participants and modellers, 


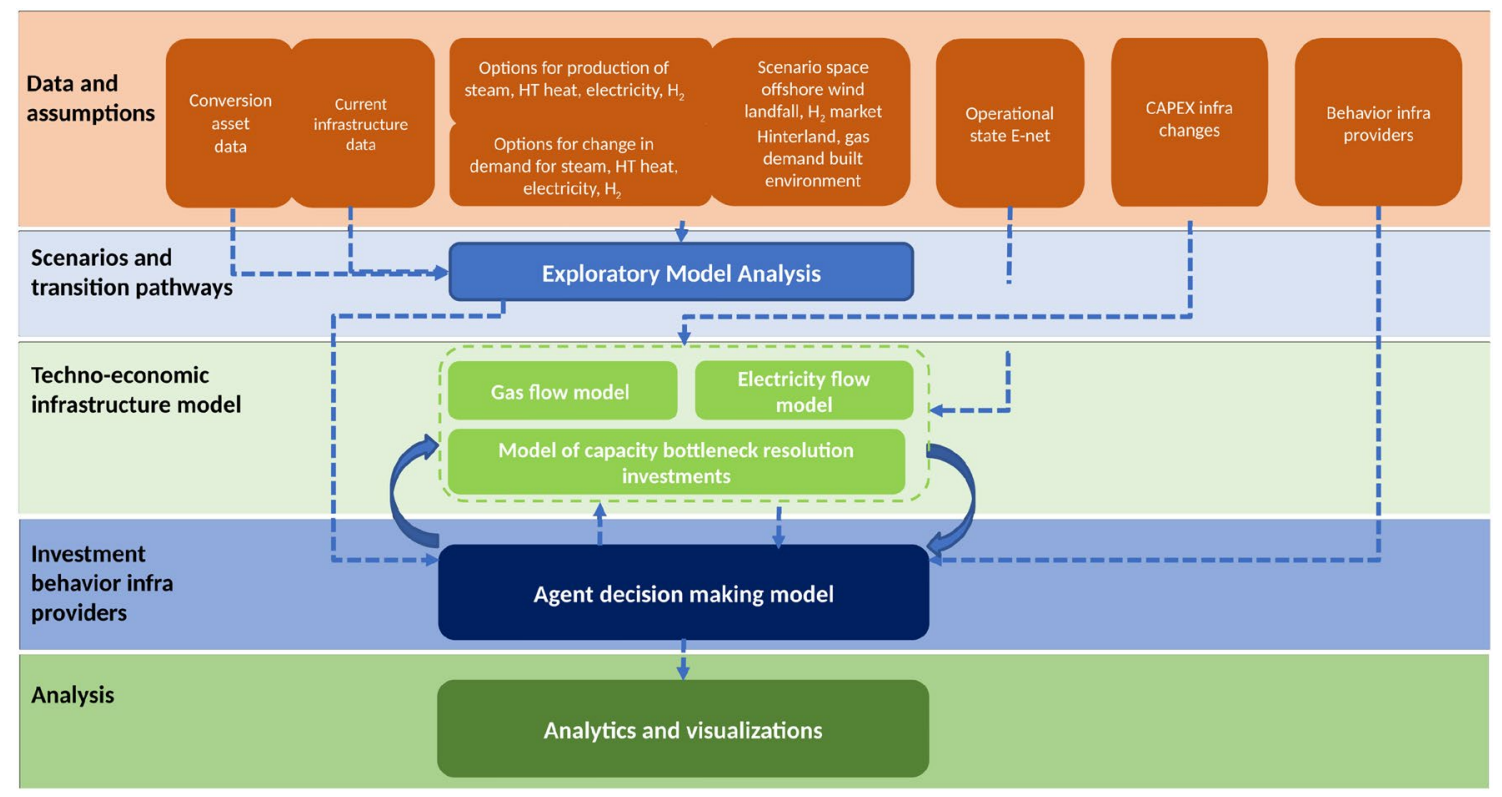

Fig. 8 High level overview of the multi-model created during the participatory modelling process. Image provided to demonstrate the nature of the boundary object, multi-model details are outside the scope of this paper

Table 4 Quantitative phase key design choices and boundary objects

\begin{tabular}{ll}
\hline Key design choices & Boundary objects \\
\hline - Using the XLRM framework & $\bullet$ XLRM framework visualisation \\
- Visualising the energy systems & $\bullet$ Energy system data visualisation \\
- Defining the missed events & $\bullet$ Model outcomes using the \\
metric & missed events metric \\
\hline
\end{tabular}

but also provided a translation among participants. Participants indicated that this visualisation, although based on public data, for the first time showed all gas and electricity networks in the area at the same time. Nothing really new was presented to them, but having their own realities presented in such a comprehensive and visual way was a drastic reminder to all of the need for collaboration and coordination in the future development of the infrastructures.

\section{Sense-making and finalisation}

The sense-making phase involved (Fig. 3) stakeholders strongly focusing on translating the relevance and utility of the constructed boundary object ecology for their own organisation. During the project finalisation, participants actively engaged with the boundary object ecology, using it to actively cross institutional field boundaries and move their organisations towards a closer collaboration. From within the created social world, and based upon specific boundary object elements created by the individuals, follow up project was defined whose purpose was to further grow the ecology and further increase the level of collaboration between organisations and institutional fields.

\section{Description of activities}

The final phase of the project consisted of the sense-making session with the participants, a closing session with broader stakeholder participation, and further finalisation activities.

The sense-making session involved a half-day workshop, during which results from the exploratory modelling scenario analysis were presented and discussed with the participants. The goal was to create a coherent, consistent and shared sense of what the exploratory modelling method entails, what kinds of outputs they produce, and what insights can be derived from this. The sense-making workshop was an important moment for the establishment of the multi-model as a boundary object ecology; it was here that participants were presented with the complete picture of process and the multi-model, where also the form and usefulness of the overall approach was established.

The workshop started by reiterating the project process, using the various boundary objects created throughout the project, such as the uncertainty space (Fig. 4), the transition pathways (Fig. 5), the XLRM diagram (Fig. 6), the connected infrastructure networks (Fig. 7), and the multi-model (Fig. 8). The reiteration closed with discussing the "missed events" metric. While visualising the (emotionally negatively charged) number of missed events is straightforward, communicating the positive message, namely what kinds of 


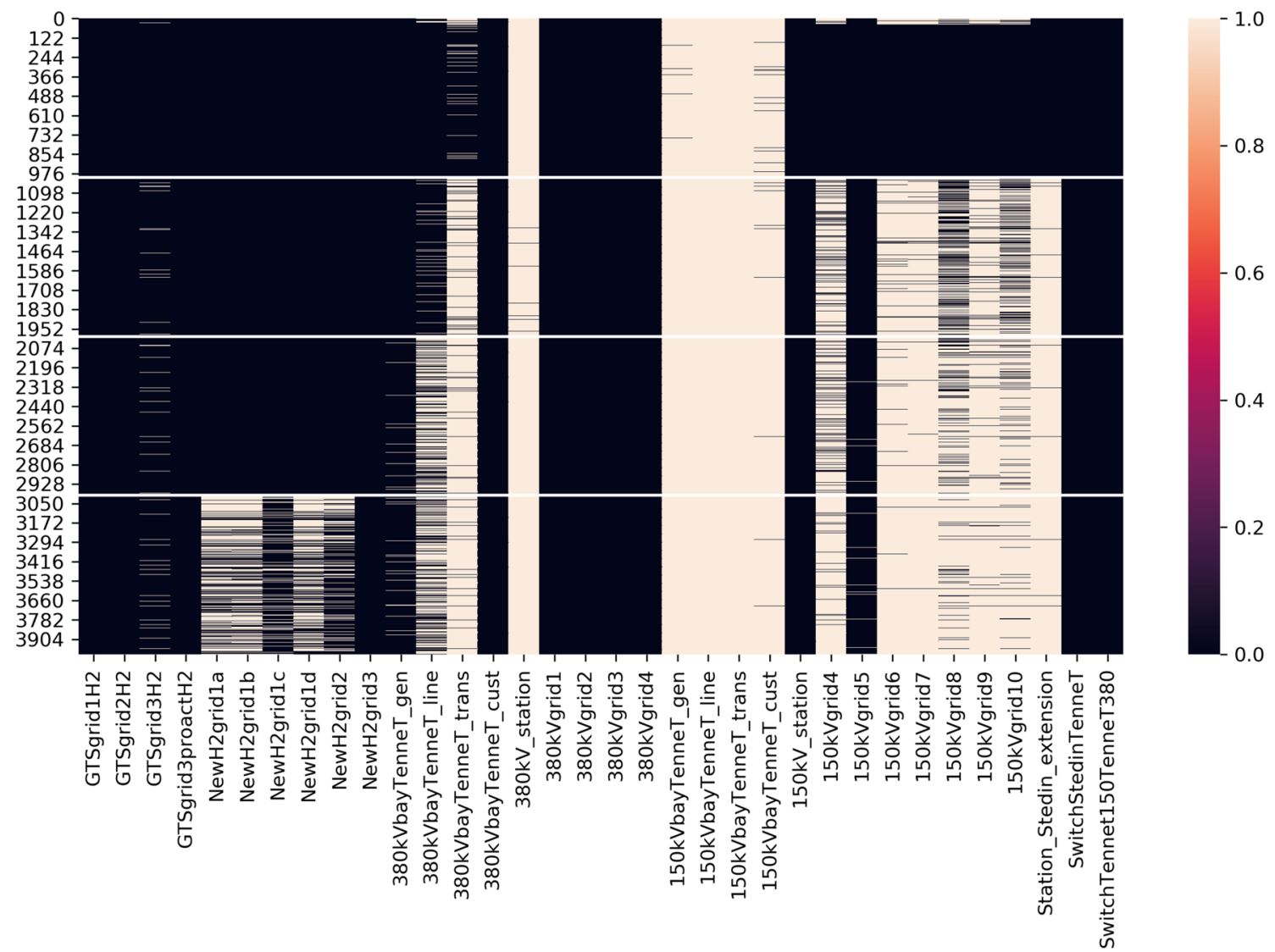

Fig. 9 Visualisation of specific investments required for supporting transition pathways. Every row is a simulation run of a transition pathway, each column a specific type of infrastructure asset. A line signifies that within this scenario pathways at least one investment of

specific investments should we do to enable the most possible futures is nontrivial. After several iterations by the project team, the visualisation in Fig. 9 was constructed. It presents the full range of policy options and infrastructure assets, many thousands of simulation runs and frequency of specific investment types over time.

The image proved to be quite problematic, as it is hard, if not impossible to interpret without a lot of background information and additional explanation. This quickly deflated the project team's enthusiasm and pride for finding a "clever" solution for presenting the data. During the process of explaining the message behind the visual, it became clear that the participants were convinced of the value of the approach followed and the outcomes. Furthermore, their dissatisfaction with the visuals; "I can't take this to my boss!" started a fruitful debate. Participants were explicitly asking the project team to help them formulate the insights and possibilities of the participatory multi-modelling approach developed in this project in a way that would help them to convince their organisations. This resulted in a simplified that type of asset has occurred. Image provided to demonstrate the nature of the boundary object, result details are outside the scope of this paper

visualisation and a selection of short narratives describing the key investment pathways qualitatively.

The last activity of the project was a half-day closing session, meant to present the results and discuss potential follow-up of the project. As the project had attracted considerable attention from senior decision-makers from the participating organisation as well as from the wider infrastructure and energy sector, the audience was larger and broader than during the sense-making session. It required an adaptation of the visualisations and narrative of the project.

The closing session ended with a discussion on possible project follow up. This led to an informal project description and commitment by stakeholders. It was decided that the current presentation would be made into a "glossy and professional" slide pack communicating the project and its outcomes to the executive boards, and to develop a project plan for follow up projects. 
Table 5 Sense-making and finalisation phase key design choices and boundary objects

\begin{tabular}{ll}
\hline Key design choices & Boundary objects \\
\hline - Visualisations and communica- & $\bullet$ XLRM framework visualisation \\
tion of the model outcomes & \\
- Explicit project follow up & $\bullet$ Pathways tree \\
& $\bullet$ Infrastructure DNA plot \\
\hline
\end{tabular}

\section{Boundary objects and translations}

Table 5 presents the key design choices and associated boundary objects during the sense-making and project finalisation phase.

During the sense-making session where the whole approach was presented, several of the boundary objects created throughout the process were re-activated, leading to a joint understanding of, and enthusiasm about, the usefulness of the participatory multi-modelling approach. The sense-making session involved translations between participants and modellers, where the boundary objects created throughout the process were activated again. Especially the pathways tree (i.e., Fig. 4) featured prominently. The discussion on how to communicate the usefulness of the approach to participants' higher management showed that, although not explicitly part of the project at this stage, participants were also translating to their organisations. This discussion was highly specific, demonstrating that the concepts and way of thinking developed in the project were internalised by the participants. By asking the question how to communicate to their organisations, they implicitly started a process of creation of several new boundary objects between the project and their respective organisations.

Translation to the organisations was more explicitly taking place during the closing session. The participants had become convinced of the proof-of-principle and were committed to a follow-up of the project. For realising this, other people had to be convinced as well. The boardroom level slide pack became an essential boundary object in the months after the project, being presented at several international infrastructure conferences, infrastructure company board meetings, and meetings with government bodies, and facilitated the formulation of three new follow up projects.

\section{Discussion}

Table 6 summarises the boundary objects constructed during the four phases of the project.

Our analysis has shown that throughout the participatory modelling process, an ecology of boundary objects emerged. The boundary objects (Table 6) were design choices that became key because they led to the establishment of boundary objects. These interacting boundary objects together created the context in which the multi-model got to function as a boundary object ecology. More systematic analysis of all design choices, and which of those lead to the establishment of boundary objects (and which do not) and why, could further support the design of participatory multi-modelling processes that allow for the creation of a boundary object ecology. This could for instance be done in quasi-experimental settings, where different design choices are systematically compared and evaluated.

An important conclusion that we can draw from the Windmaster process, is that for the multi-model to function as a boundary object ecology, it appeared important to design for translations between participants, and between participants and their organisation. It would be interesting to investigate in more detail for what particular types of participatory processes this is the case. It probably has to do with the shared sense of urgency perceived by the infrastructure providers to find a way to deal with the infrastructure challenges they are facing, the high stakes, and the lacking capability of current decision-support tools to support decisionmaking on these particular challenges. Comparative research could shed more light on this.

If we reflect on the design of the Windmaster participatory multi-modelling process, two issues emerge that deserve further investigation. Firstly, the composition of the participants group. All participants had deep knowledge

Table 6 Identified boundary objects per phase

\begin{tabular}{|c|c|c|c|}
\hline Pre-project proposal & Qualitative & Quantitative & Sense-making \\
\hline - slide pack & - visions & - XLRM framework visualisation, & $\begin{array}{l}\text { - Most previous } \\
\text { boundary } \\
\text { objects }\end{array}$ \\
\hline - the project specification in the proposal & - pathways & - energy system data visualisation & - Multi-model \\
\hline - visualisations & - time horizon of 2050 & - missed event metric & \\
\hline - the time horizon of 2030 & - Go / NoGo documentation & & \\
\hline $\begin{array}{l}\text { - uncertainty space visualization: adaptive } \\
\text { pathways tree }\end{array}$ & & & \\
\hline
\end{tabular}


about infrastructures and were accustomed to modelling, and thus able to quickly internalise the modelling work. On the one hand, this suggests that the identification of participants is a crucial step for participatory multi-modelling. On the other hand, it shows that further research is needed to develop a more fine-grained understanding of the conditions under which such a participatory multi-modelling approach is viable and effective.

Secondly, the composition of the research team. The team combined expertise on multi-modelling and expertise on social processes and facilitation, and, importantly, the members of the team are well experienced in working in such an interdisciplinary team. This greatly benefited the design of the participatory multi-modelling process. The project team contained two individuals, one on the academic and one on the practitioner side who jointly took the lead in the development of the project. These project team members acted as boundary workers (McMillan 2011) Boundary workers are individuals that are comfortable bridging the gap between industry and academia, commercial and nonprofit, etc and translating each others understanding of the world and the involved boundary objects. Countless choices, decisions and tweaks to the design, process, communication etc were made in frequent interactions between these individuals, with the explicit goal to find translations and alignment between the different social worlds. More than we initially realised, this concerned not only translations between individuals and modellers in the process, but also between individuals and their organisations. This suggests that involving people in the research team who can span different boundaries at the same time, and who are sensitive to the needs, norms and language of the social worlds of organisations and institutional fields is key to a successful participatory multi-modelling process. Also a more fine-grained understanding is needed of how this contributes to the conditions under which a participatory multi-modelling approach is effective. Next to stakeholders and domain experts it is essential to involve individuals who can function as boundary workers. Such individuals can greatly reduce misunderstandings by translating language, identifying sensitivities and aligning social norms between different social worlds. While different types of boundary workers exist (Hoppe 2009) a basic requirement would be that these individuals are willing and capable of transgressing the boundary between academia and industry (and/or government), and having a lead in the process design to allow for meaningful boundary transgression.

\section{Conclusion}

This paper aimed to answer the question what design choices were key to the functioning of the participatory multimodelling process as a process of boundary object ecology creation in the Windmaster project. We identified a number of design choices in each phase of the project. We can conclude that there are design choices that facilitate (1) translations between participants and (2) translations between participants and their organisation. Our results show that these design choices created boundary objects in different phases of the process that were critical to the functioning of the multi-model as a boundary object ecology. We conclude that participatory multi-modelling is a process in which there is not one, but multiple co-evolving boundary objects that interact to create an emergent, higher-order boundary object ecology, i.e. the multi-model itself. We argued that further research is needed to more systematically investigate how the exploratory notions developed in this paper can be used to design participatory multi-modelling processes more effectively so that they can serve as leverage points for sustainable transformation.

Acknowledgements The authors would in particular like to acknowledge Ton Wurth, Maarten Sloot and Johan Bogerd for their indispensable work and input in the project. They also would like to thank the representatives from the funding organisations for their participation, time and inputs to the project and participatory modelling process.

Funding The Windmaster project has been executed in the period October 2018-May 2019, and was funded by Tennet, Gasunie, Stedin, Province of South Holland and Rotterdam port Authority. Siemens and TU Delft executed the project, with participation from the funding organisations.

Open Access This article is licensed under a Creative Commons Attribution 4.0 International License, which permits use, sharing, adaptation, distribution and reproduction in any medium or format, as long as you give appropriate credit to the original author(s) and the source, provide a link to the Creative Commons licence, and indicate if changes were made. The images or other third party material in this article are included in the article's Creative Commons licence, unless indicated otherwise in a credit line to the material. If material is not included in the article's Creative Commons licence and your intended use is not permitted by statutory regulation or exceeds the permitted use, you will need to obtain permission directly from the copyright holder. To view a copy of this licence, visit http://creativecommons.org/licenses/by/4.0/.

\section{References}

Argyris C (2002) Double-loop learning, teaching, and research. Acad Manag Learn Educ 1(2): 206-218. Retrieved 2020-01-26, from https://doi.org/10.5465/amle.2002.8509400

Arnstein SR (1969) A ladder of citizen participation. J Am Inst Planners 35(4):216-224

Ashby WR (1968) Variety, constraint, and the law of requisite variety. In: Systems research for behavioral science. Routledge, pp $129-136$

Bankes S (1993) Exploratory modeling for policy analysis. Oper Res 4(3):435-449. https://doi.org/10.1287/opre.41.3.435

Bankes S, Walker E, Warren and Kwakkel JH (2013) Exploratory modeling and analysis. In: Gass SI, Fu MC (eds) Encyclopedia of operations research and management science. Springer, US, Boston, MA 
Barreteau O, Abrami G, Dare W, Du Toit D, Ferrand N, Garin P, Flaxman M (2012) Collaborative modelling as a boundary institution to handle institutional complexities in water management. In Karl HA, Scarlett L, Vargas-Moreno JC (eds.), Restoring lands - coordinating science, politics and action: Complexities ofclimate and governance. Springer, Netherlands pp 109-127. Retrieved from https://doi.org/10.1007/978-94-007-2549-2_6

Barreteau O, Bots P, Daniell K, Etienne M, Perez P, Barnaud C (2013) Participatory approaches. In: Simulating social complexity. Springer, pp. 197-234

Barreteau O, Bots PW, Daniell KA (2010) A framework for clarifying "participation" in participatory research to prevent its rejection for the wrong reasons. Ecology and Society 15(2):

Basco-Carrera L, Warren A, van Beek E, Jonoski A, Giardino A (2017) Collaborative modelling or participatory modelling? a framework for water resources management. Environm Model Softw 91:95-110

Bollinger L, Davis C, Evins R, Chappin E, Nikolic I (2018) Multimodel ecologies for shaping future energy systems: Design patterns and development paths. Renew Sustain Energy Rev 82:3441-3451

Bollinger LA, Nikolic I, Davis CB, Dijkema GP (2015) Multi-model ecologies: cultivating model ecosystems in industrial ecology. J Industr Ecol 19(2):252-263

Breukers S, Hisschemoller M, Cuppen E, Suurs R (2014) Analysing the past and exploring the future of sustainable biomass. participatory stakeholder dialogue and technological innovation systems research. Technological Forecasting and Social Change, 81: 227 235. Retrieved 2019-10-07, from http://www.sciencedirect.com/ science/article/pii/ S0040162513000280https://doi.org/10.1016/j. techfore.2013.02.004

Calder M, Craig C, Culley D, Cani Rd, Donnelly CA, Douglas R, Wilson A (2018). Computational modelling for decision-making: where, why, what, who and how. Open Sci 5(6): 172096. Retrieved Oct 9 2018, from http://rsos.royalsocietypublishing.org/ content/5/ 6/172096https://doi.org/10.1098/rsos.172096

Callon M (1984) Some elements of a sociology of translation: Domestication of the scallops and the fishermen of st brieuc bay. Sociol Rev 32(1):196-233. Retrieved 7 Oct 2019, from https://doi. org/10.1111/j.1467-954X.1984.tb00113.x

Castelletti A, Soncini-Sessa R (2007) Bayesian networks and participatory modelling in water resource management. Environm Model Softw 22(8):1075-1088

Cuppen E (2012a) Diversity and constructive conflict in stakeholder dialogue: considerations for design and methods. Policy Sci 45(1):23-46

Cuppen E (2012b) A quasi-experimental evaluation of learning in a stakeholder dialogue on bio-energy. Res Policy 41(3):624-637

Cuppen E, Breukers S, Hisschemoller M, Bergsma E (2010) Q methodology to select participants for a stakeholder dialogue on energy options from biomass in the netherlands. Ecolog Econom 69(3):579-591

Dam KHv, Nikolic I, Lukszo Z. (Eds.). (2013). Agent-based modelling of socio-technical systems. Springer, Netherlands. Retrieved 2018-10-31, from //www.springer.com/gp/book/9789400749320

de Bruijn T, Tukker A (2002) Partnership and leadership: Building alliances for a sustainable future, Vol 8. Springer Science and Business Media

DiMaggio PJ, Powell WW (1983) The iron cage revisited: Institutional isomorphism and collective rationality in organizational fields. Am Sociolog Rev 48(2): 147-160. Retrieved 7 Oct 2019, from https://www.jstor.org/stable/2095101https://doi. org/10.2307/2095101

Feldhoff B, Stockmann N, Fanderl N, Gahle A-K, Graf A, Leger M, Sonnberger M (2019). Bridging theories and practices: Boundary objects and constellation analysis as vehicles for interdisciplinary knowledge integration. Sustainability, 11 (19):5357. Retrieved 33 Jan 2020, from https://doi.org/10.3390/su11195357

Green SE, Babb M, Alpaslan CM (2008) Institutional field dynamics and the competition between institutional logics: The role of rhetoric in the evolving control of the modern corporation. Manag Commun Quarterly 22(1):40-73. Retrieved 7 Oct 2019, from https ://doi.org/10.1177/0893318908318430

Haasnoot M, Kwakkel J, Walker WE, ter Maat J (2013). Dynamic adaptive policy pathways: A method for crafting robust decisions for a deeply uncertain world. Global Environm Change 23(2): 485498. Retrieved from http://www.sciencedirect.com/science/ article/pii/S095937801200146Xhttps://doi.org/10.1016/j.gloen vcha.2012.12.006

Henly-Shepard S, Gray SA, Cox LJ (2015) The use of participatory modeling to promote social learning and facilitate community disaster planning. Environm Sci Policy 45:109-122

Herman J, Reed PM, Zeff H, Characklis G (2015) How should robustness be defined for water systems planning under change. J Water Resour Plann Manag https://doi.org/10.1061/(ASCE)WR.19435452.0000509

Hodges J (1991) Six (or so) things you can do with a bad model. Oper Res 39(3):355-365

Hoppe R (2009) Scientific advice and public policy: expert advisers' and policymakers' discourses on boundary work. Poiesis Praxis 6(3-4):235263

Jakku E, Thorburn P (2010) A conceptual framework for guiding the participatory development of agricultural decision support systems. Agricul syst 103(9):675-682

Kimble C, Grenier C, Goglio-Primard K (n.d.) Innovation and knowledge sharing across professional boundaries: Political interplay between boundary objects and brokers. Int J Inform Manag 30(5): 437-444. Retrieved 22 Jan 2020, from https:// www.sciencedirect.com/science/article/abs/pii/S026840121 0000277https://doi.org/10.1016/j.ijinfomgt.2010.02.002

Kwakkel J, Haasnoot M (2019) Supporting dmdu: A taxonomy of approaches and tools. In: Marchau V, Walker W, Bloemen P, Popper S (eds.) Decision making under deep uncertainty - from theory to practice. Springer. https://doi.org/10.1007/978-3-03005252-2 15

Kwakkel J, Haasnoot M, Walker WE (2016) Coping with the wickedness of public policy problems: Approaches for decisionmaking under deep uncertainty. J Water Resour Plann Manag 142(3):

Kwakkel J, Pruyt E (2013) Exploratory modeling and analysis, an approach for model-based foresight under deep uncertainty. Technolog Forecast Social Change 80(3):419-431. https://doi. org/10.1016/j.techfore.2012.10.005

Kwakkel J, Walker WE, Marchau V (2010). Classifying and communicating uncertainties in model-based policy analysis. Int $\mathrm{J}$ Technol Policy Manag 10(4): 299-315. https://doi.org/10.1504/ IJTPM.2010.036918

Lempert RJ (2003) Shaping the next one hundred years: New methods for quantitative, long-term policy analysis. Rand Corporation. (Google-Books-ID: F2SzOwE0 \bIC)

Ligtvoet A, Cuppen E, Di Ruggero O, Hemmes K, Pesch U, Quist J, Mehos D (2016). New future perspectives through constructive conflict: Exploring the future of gas in the Netherlands. Futures, 78-79, 19-33. Retrieved 327 Oct 2019, from http://www.scien cedirect.com/science/article/pii/ S0016328715300240https:// doi.org/10.1016/j.futures.2016.03.008

Loorbach D, Frantzeskaki N, Avelino F (2017) Sustainability transitions research: transforming science and practice for societal change. Ann Rev Environm Resour 42

Lynam T, De Jong W, Sheil D, Kusumanto T, Evans K (2007) A review of tools for incorporating community knowledge, 
preferences, and values into decision making in natural resources management. Ecol Soc 12(1)

McMillan J (2011) Boundary workers and their importance to community-university partnerships. Metropolitan Universities, 22(2): 106-120. Retrieved 26 Jan 2020, from https://journals. iupui.edu/index.php/muj/article/ view/20476

Meadows D (2008) Thinking in systems. Chelsee Green Publishing, White River Junction, Vermont

Mikulecky D (2001) The emergence of complexity: science coming of age or science growing old? Computers Chem 25(4):341-348

Mitchell S (2003) Biological complexity and integrative pluralism. Cambridge

Nicolini D, Mengis J, Swan J (2011) Understanding the role of objects in cross-disciplinary collaboration. Organiz Sci 23(3):612-629. Retrieved 22 Jan 2020, from https://doi. org/10.1287/orsc. 1110.0664

Niesten E, Jolink A, de Sousa Jabbour ABL, Chappin M, Lozano R (2017) Sustainable collaboration: The impact of governance and institutions on sustainable performance. J Clean Prod 155:1-6

Nikolic I, Kwakkel J, Chappin E, Lukszo Z, Brazier F, Verbraeck A (2019) Principles, challenges and guidelines for a multi-model ecology (White paper). Faculty of TPM, TU Delft. Retrieved from https://doi.org/10.4233/uuid:1aa3d16c-2acd-40ce-b6b8$0712 \mathrm{fd} 947840$

Pahl-Wostl C, Hare M (2004) Processes of social learning in integrated resources management. J Community Appl Soc Psychol 14(3):193-206

Pretty JN (1995) Participatory learning for sustainable agriculture. World develop 23(8):1247-1263

Quist J (2013) Backcasting and scenarios for sustainable technology development. Handbook of Sustain Eng 749-771

Quist J, Vergragt P (2006) Past and future of backcasting: the shift to stakeholder participation and a proposal for a methodological framework. Futures 38(9):1027-1045

Rittel HW, Webber MM (1974) Wicked problems. Man-made. Futures 26(1):272-280

Rockmann C, Ulrich C, Dreyer M, Bell E, Borodzicz E, Haapasaari $P$ (2012) The added value of participatory modelling in fisheries management-what has been learnt? Marine Policy 36(5):1072-1085

Star SL, Griesemer JR (1989) Institutional ecology, 'translations' and boundary objects: Amateurs and professionals in berkeley's museum of vertebrate zoology, 1907-39. Social Studies of Science, 19 (3), 387-420. Retrieved 9 April 2019, from https://doi. org/10.1177/030631289019003001

Strauss A (1982) Social worlds and legitimation processes. Stud Symb Inter 4(17): 121

Trompette P, Vinck D (2009) Revisiting the notion of boundary object. Revue d'anthropologie des connaissances. 3(1): 3-25. Retrieved 2020-01-28, from https://www.cairn.info/revue-anthropologiedes-connaissances-2009-1-page-3.htm

van Asselt Marjolein B, Rijkens-Klomp N (2002) A look in the mirror: reflection on participation in integrated assessment from a methodological perspective. Global Environm Change 12(3):167-184 van Bruggen A, Nikolic I, Kwakkel J (2019) Modeling with stakeholders for transformative change. Sustainability 11(3): 825 Retrieved 24 Feb 2019, from https://www.mdpi.com/20711050/11/3/825https://doi.org/10.3390/su11030825

Van der Lei TE, Bekebrede G, Nikolic I (2010) Critical infrastructures: a review from a complex adaptive systems perspective. Int J Crit Infrastruc 6(4):380-401

van der Voorn T, Quist J, Pahl-Wostl C, Haasnoot M (2007) Envisioning robust climate change adaptation futures for coastal regions: a comparative evaluation of cases in three continents. Mitigation and adaptation strate-giesfor global change. 22(3): 519-546. Retrieved 24 Jan 2020, from https://doi.org/10.1007/ s11027-015-9686-4

Vennix J (1999) Group model-building: tackling messy problems. Syst Dynam Rev 15(4):37-401

Vergragt PJ, Quist J (2011) Backcasting for sustainability: Introduction to the special issue. Technol Forecast Social Change 78:747-755

Vernay A-L, Boons F (2015) Assessing systems integration: A conceptual framework and a method. Syst Res Behav Sci 32(1):106-123. Retrieved from https://doi.org/10.1002/sres.2221

Videira N, Antunes P, Santos R (2009) Scoping river basin management issues with participatory modelling: the baixo guadiana experience. Ecolog Econom 68(4):965-978

Voinov A, Bousquet F (2010) Modelling with stakeholders. Environm Model Softw 25(11):1268-1281

Voinov A, Kolagani N, McCall M, Glynn P, Kragt M, Ostermann F, Ramu P (2016) Modelling with stakeholders - next generation. Environm Model Softw 77:196-220. https://doi.org/10.1016/j. envsoft.2015.11.016

Walker WE, Haasnoot M, Kwakkel J (2013) Adapt or perish: A review of planning approaches for adaptation under deep uncertainty. Sustainability 5(3):955-979. https://doi.org/10.3390/su5030955

Walker WE, Lempert RJ, Kwakkel JH (2013) Deep uncertainty. In S. I. Gass \& M. C. Fu (Eds.), Encyclopedia of operations research and management science. Springer, Boston, pp. 395-402. Retrieved from https://doi.org/10.1007/978-1-4419-1153-7_1140

Wurth T, Nikolic I, Kwakkel J, Sloot M, Cuppen E, Quist J (2019) Eindrapportage project windmaster: De weg naar een adaptief investerings-beleid. Delft University of Technology. (Opdrachtgevers: Gasunie, Ten-neT, Stedin, Port of Rotterdam, Provincie Zuid-Holland) https://doi.org/10.4233/uuid:122661d9-65eb-4d3ab91a-2721dcacaaba

Yearley S, Cinderby S, Forrester J, Bailey P, Rosen P (2003) Participatory modelling and the local governance of the politics of uk air pollution: a three-city case study. Environm Values 12(2): $247-262$

Publisher's Note Springer Nature remains neutral with regard to jurisdictional claims in published maps and institutional affiliations. 